\title{
High extracellular potassium and its correlates after severe head injury: relationship to high intracranial pressure
}

\author{
Michael Reinert, M.D., Ahmad Khaldi, B.S., Alois Zauner, M.D., \\ Egon Doppenberg, M.D., Sung Choi, Ph.D., And Ross Bullock, M.D., Ph.D. \\ Division of Neurosurgery and Department of Biostatistics, Medical College of Virginia, \\ Virginia Commonwealth University, Richmond, Virginia
}

\begin{abstract}
Disturbed ionic and neurotransmitter homeostasis are now recognized to be probably the most important mechanisms contributing to the development of secondary brain swelling after traumatic brian injury (TBI). Evidence obtained from animal models indicates that posttraumatic neuronal excitation via excitatory amino acids leads to an increase in extracellular potassium, probably due to ion channel activation. The purpose of this study was therefore to measure dialysate potassium in severely head injured patients and to correlate these results with intracranial pressure (ICP), outcome, and also with the levels of dialysate glutamate, lactate, and cerebral blood flow (CBF) so as to determine the role of ischemia in this posttraumatic ionic dysfunction.

Eighty-five patients with severe TBI (Glasgow Coma Scale score $<8$ ) were treated according to an intensive ICP management-focused protocol. All patients underwent intracerebral microdialyis. Dialysate potassium levels were analyzed by flame photometry, as were dialysate glutamate and dialysate lactate levels, which were measured using high-performance liquid chromatography and an enzyme-linked amperometric method in 72 and 84 patients respectively. Cerebral blood flow studies (stable Xenon--computerized tomography scanning) were performed in 59 patients.

In approximately $20 \%$ of the patients, potassium values were increased (dialysate potassium $>1.8 \mathrm{mmol}$ ). Mean dialysate potassium ( $>2 \mathrm{mmol}$ ) was associated with ICP above $30 \mathrm{~mm} \mathrm{Hg}$ and fatal outcome. Dialysate potassium correlated positively with dialysate glutamate $(\mathrm{p}<0.0001)$ and lactate levels $(\mathrm{p}<0.0001)$. Dialysate potassium was significantly inversely correlated with reduced CBF $(\mathrm{p}=0.019)$.

Dialysate potassium was increased after TBI in $20 \%$ of measurements. High levels of dialysate potassium were associated with increased ICP and poor outcome. The simultaneous increase of potassium, together with dialysate glutamate and lactate, supports the hypothesis that glutamate induces ionic flux and consequently increases ICP due to astrocytic swelling. Reduced CBF was also significantly correlated with increased levels of dialysate potassium. This may be due to either cell swelling or altered potassium reactivity in cerebral blood vessels after trauma.
\end{abstract}

\section{KEY WORDS • potassium • glutamate • lactate • cerebral blood flow • severe head injury - intracranial pressure}

Severe TBI leads to a sudden neuronal discharge-traumatic depolarization. ${ }^{10,17,25}$ As in any depolarizing cell, this results in an extracellular increase in potassium in exchange with sodium, which moves into the cell. Methods such as patch-clamp techniques or $\mathrm{K}^{+}$-sensitive microelectrodes can be used to measure these millisecond physiological changes. ${ }^{12,14}$ The traumatic depolarization encountered after TBI, however, is a longer-lasting phenomenon. Patch-clamp studies have shown that traumatic

\footnotetext{
Abbreviations used in this paper: AMPA = 2-amino-3--hydroxy5-methylisoxazole-4-propionic acid; ATP = adensoine triphosphate; $\mathrm{CBF}=$ cerebral blood flow; $\mathrm{CT}=$ computerized tomography; $\mathrm{ECF}=$ extracellular fluid; GOS = Glasgow Outcome Scale; ICP = intracranial pressure; NMDA $=\mathrm{N}$-methyl-D-asparate; $\mathrm{rCBF}=$ regional $\mathrm{CBF}$; $\mathrm{SEM}=$ standard error of the mean; $\mathrm{TBI}=$ traumatic brain injury.
}

depolarization persists for up to 24 hours in vitro. ${ }^{43}$ Using microdialysis, Katayama, et al., ${ }^{16}$ have demonstrated that after rat fluid-percussion injury, the increase in dialysate potassium was dependent on the magnitude of the injury. In cases of fatal fluid-percussion injury, potassium levels remained elevated but did not revert to baseline as observed in those with less severe injuries. This late increase was attributed to membrane breakdown and cell death, with failure to repolarize the membrane. It can be hypothesized that several different mechanisms can lead to an increase in dialysate potassium: 1) brief, transient membrane microporation by mechanical stress without membrane disruption;6,16 2) potassium flux through voltagegated and agonist-activated channels such as NMDA and AMPA receptors; ;11,16,17 3) nonspecific membrane breakdown, as part of cell rupture and necrosis; and 4) ischemic depolarization due to inadequate $\mathrm{CBF}$ and consequent ATP reduction. 
Astrocytes as neuronal energy providers and maintainers of ECF homeostasis are especially exposed to the influence of increased ECF $\left[\mathrm{K}^{+}\right],{ }^{9,24,30,31}$ and they have been shown to respond to increased $\left[\mathrm{K}^{+}\right]$by marked cell swelling. It has been shown that increasing extracellular potassium experimentally from 3 to $6 \mathrm{mmol}$ causes normal astrocytes to swell to several times their normal volume. ${ }^{26}$ This is an important mechanism by which the increase in extracellular potassium is buffered to allow membrane repolarization. This mechanism may also influence CBF, because astrocytic perivascular foot processes have been shown to swell enough to compress the microvessels. ${ }^{29}$ Paulson and Newman ${ }^{28}$ have shown that potassium is taken up by astrocytes and transported into the endfeet of astrocytes surrounding blood vessels, thus causing them to swell, and that this may derange the normal cerebrovascular reactivity in the presence of increased extracellular potassium, as seen after severe head injury. ${ }^{2,3,15}$

By using microdialysis, we have previously shown that glutamate is markedly increased after human TBI. ${ }^{7}$ In this study, we have therefore chosen to explore the possible consequences of glutamate release by testing the hypotheses that: 1) dialysate glutamate may be linked with dialysate potassium an indicator of ionic flux, caused by ionchannel activation; 2) dialysate potassium will be a determinant of elevated ICP via the mechanisms of astrocytic swelling, outlined previously; and 3) low rCBF will be related to increases in dialysate potassium, due to ischemic depolarization.

To test these hypotheses we have studied 85 severely head injured patients by using continuous intracerebral microdialysis, and we have related the ionic and neurochemical data to clinical parameters, ICP, and outcome.

\section{CLINICAL MATERIAL AND METHODS}

All studies were approved by the Committee for conduct of Human Research at the Virginia Commonwealth University.

\section{Patient Population}

We studied 85 patients ( $>16$ years of age) with severe head injury, who were admitted to the Neuroscience Intensive Care Unit at the Medical College of Virginia, with a Glasgow Coma Scale score equal to or less than 8. All patients received intensive ICP-directed management according to a standard protocol at our institution. Patients who were brain dead or close to brain death on admission or for whom informed consent could not be obtained were excluded from this study.

\section{Cerebral Blood Flow Measurements}

Stable xenon-enhanced CT scanning was used for measuring $\mathrm{CBF}$ and was performed by repeated CT scanning during the inhalation of a gas mixture containing $30 \%$ xenon, 30 to $60 \%$ oxygen, and room air. Regional CBF was calculated using a 20-mm-diameter region of interest placed at the site where the microdialysis probe was seen on the CT scan. End tidal $\mathrm{CO}_{2}$ was kept as near as possible to $30 \mathrm{~mm} \mathrm{Hg}$ to optimize comparison between patients and to control the ICP during the CBF study.

\section{Microdialysis Procedure}

A custom-built 51-mm flexible microdialysis probe with an external diameter of $1.5 \mathrm{~mm}$ and a molecular weight cutoff of 20,000 daltons was used to determine cortical levels of glutamate, lactate, and potassium. The probe was placed in a standard fashion through a custombuilt triple lumen bolt that was tapped and screwed into the right frontal skull and that carried the ventriculostomy catheter. In some cases, as when a hematoma was removed at surgery, the microdialysis probe was inserted through a craniotomy. The microdialysis probe was perfused at $2 \mu \mathrm{l}$ per minute by using sterile $0.9 \%$ saline. Sixty-microliter dialysates were collected every $30 \mathrm{~min}-$ utes into sealed glass tubes by using a refrigerated $\left(4^{\circ} \mathrm{C}\right)$ automated collector system. The microdialysis probe was allowed to stabilize for 2 hours, prior to being used to collect the dialysate samples for analysis. The microdialysis probe was saved after removal for in vitro calibration. Glutamate and lactate were measured using high-performance liquid chromatography and with the YellowSpring amperometric analyzer, respectively.

\section{In Vitro Recovery for Microdialysis Probe}

After we used our custom-made microdialysis probes, they were stored in saline and later analyzed for in vitro recovery. The in vitro recovery rate for potassium was $65 \pm 16 \%$ (SEM). All potassium values refer to microdialysate potassium values unless otherwise specified.

\section{Potassium Measurements}

Potassium measurements in dialysate were performed using a Flame photometer.

\section{Outcome Analysis}

The relationship between outcome and levels of dialysate potassium was tested using a modified GOS score at the 3 month follow up. Three outcome groups were defined as good (GOS scores of 0 and 1), poor (GOS scores of 2 and 3), and death (GOS score of 4). An unpaired t-test was used to determine significance.

\section{Intracranial Pressure Analysis}

Intracranial pressure was monitored using an intraventricular catheter and an external strain gauge pressure device. To analyze the relationship between potassium and ICP, three groups were arbitrarily defined: 1 ) mean ICP less than $20 \mathrm{~mm} \mathrm{Hg}$; 2) mean ICP from 20 to $30 \mathrm{~mm} \mathrm{Hg}$; and 3) mean ICP greater than $30 \mathrm{~mm} \mathrm{Hg}$. An unpaired t-test was used to determine significance. The mean ICP was calculated in each patient by recording the ICP closest to the time point at which $\mathrm{K}^{+}$was measured in the dialysate and by obtaining the mean of these values over the course of microdialysis.

\section{Statistical Analysis}

Microdialysis measurements for potassium, obtained for 6 hours before until 6 hours after the CBF study, were averaged for comparison with the rCBF results. Regression analysis and Spearman rank correlation tests were used to test the interrelationships between these parameters. 


\section{Extracellular potassium and its relationship to high ICP}

To study the relationships between glutamate-potassium and lactate-potassium, the regression coefficients (" $\mathrm{r}$ values") for each patient were calculated. In this way the "nature" (positive or negative) of the relationship could be determined. This was followed by a one sample t-test, performed over these $r$ values to test the significance of these regression results. Values are represented as the mean \pm SEM.

The analysis of variance test was used to test the significance of the difference between extracellular potassium in patients with contusions as compared with those without contusions. To compute the data from the database, the Microsoft Access program was used.

\section{Sources of Supplies and Equipment}

We obtained a xenon-enhanced CT scanner (Xe CT Enhancer 300) from Diversified Diagnostic Procucts, Inc. (Houston, TX). The custom-built flexible microdialysis probe was manufactured by CMA Microdialysis (Acton, MA). The dialysates were collected using an automated collector system acquired from BAS Honeycomb (West Lafayette, IN). Potassium levels were measured using a photometer (IL 943 Automatic Flame Photometer) obtained from Instrumentation Laboratory Inc. (Lexington, MA). We used the Microsoft Access program (Microsoft, Seattle, WA) to compute the data from the database.

\section{RESULTS}

\section{Potassium Measurements}

Although there are no normal data regarding the expected levels of dialysate potassium in the human brain, extrapolation from the studies of Nilsson,et al., ${ }^{27}$ Katayama and associates, ${ }^{16,17}$ and Marmarou (unpublished data) in the normal rat brain suggests that the normal dialysate potassium level should be below $1.8 \mathrm{mmol} / \mathrm{l}$, by using our $2 \mu \mathrm{l} /$ minute perfusion system. This is based upon an ECF $\mathrm{K}^{+}$mean value of $3 \mathrm{mM}$ and a dialysate $\mathrm{K}^{+}$recovery for our system of $65 \pm 16 \%$ (SEM), which has been shown to vary by not more than $10 \%$ in numerous in vitro probe recovery experiments with the CMA 20 custom-made dialysis probes. In $12 \%$ of our 85 patients with severe TBI, dialysate potassium levels remained consistently over 1.8 $\mathrm{mM}$ throughout the monitoring period. In $20.8 \%$ of these patients with severe TBI, dialysate potassium levels were greater than or equal to $1.8 \mathrm{mM}$ for a certain time period (Fig. 1). In $22.9 \%$ of patients, dialysate potassium levels were higher than $1.8 \mathrm{mM}$ at least at one time point.

\section{Case Examples}

The graphs in Fig. 2 depict the measurements obtained in two patients of dialysate potassium, glutamate, and lactate compared with time after injury. In the case represented as Patient A, high glutamate is associated with high lactate and high potassium values, as well as poor outcome; in the case represented as patient B, low glutamate is associated with low lactate, low potassium, and good outcome.

\section{Effect of Type of Injury on Potassium Levels}

When the patients were separated into those with and without focal contusions located at the site of the microdialysis probe as identified on CT studies, two patterns could be observed. In patients with contusions significantly higher initial mean dialysate potassium values were demonstrated within the first 24 hours after initiation of monitoring than in those with a diffuse brain injury $(\mathrm{p}=$ 0.014) (Fig. 3). During the subsequent 3 days of the monitoring period, this difference, however, disappeared.

\section{Potassium and its Relationship With Glutamate}

In 72 patients, the regression relationship between potassium and glutamate was tested. The mean $\mathrm{r}$ value was $0.206 \pm 0.04(\mathrm{SEM})$, which demonstrates a positive correlation between glutamate and potassium. The histogram depicting the distribution of the $r$ values is shown

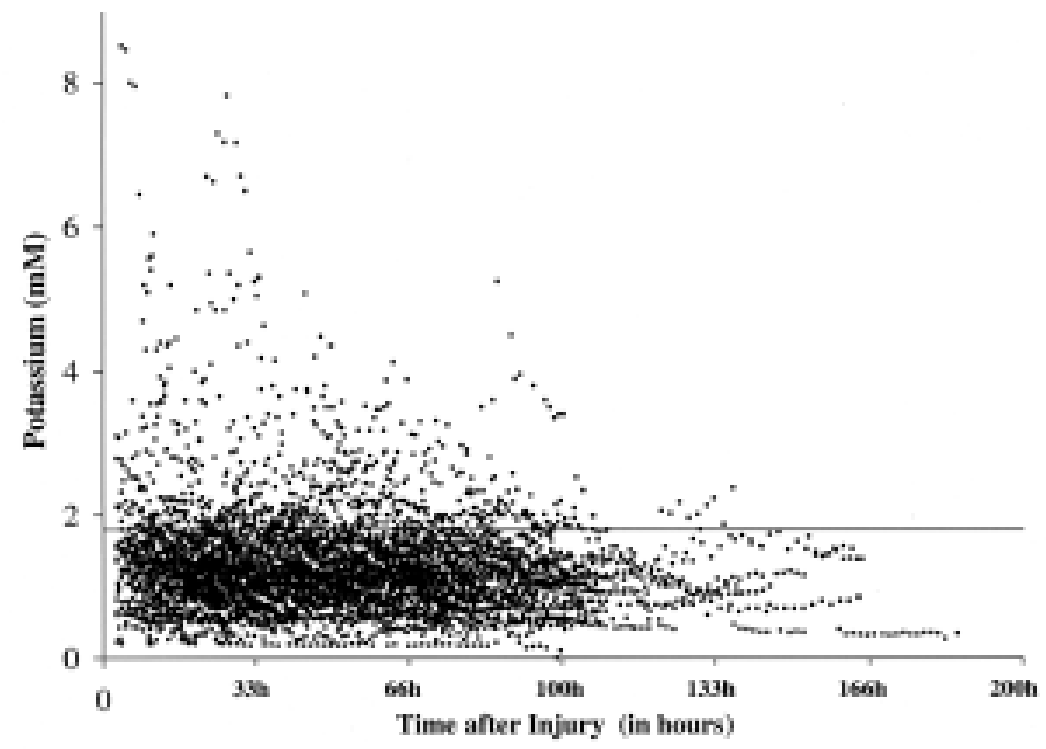

Fig. 1. Distribution of the dialysate potassium values obtained from all 83 patients over time after injury; $22.9 \%$ of all potassium values were over $1.8 \mathrm{mmol} / \mathrm{l}$. 
in Fig. 4 upper. A highly significant association was shown when a one-sample t-test was performed over the group as a whole ( $\mathrm{p}<0.0001,72$ patients).

\section{Potassium and its Relationship With Lactate}

In 84 patients, potassium and lactate levels were measured during the microdialysis period and were similarly analyzed. The mean $r$ value was $0.226 \pm 0.044$ (SEM), demonstrating a positive correlation between lactate and potassium. Figure 4 center shows the histogram of the distribution of the $r$ values. The one-sample t-test demonstrated a highly significant association $(\mathrm{p}=0.0001)$.

\section{Relationship of Glutamate and Lactate}

In 85 patients the relationship between glutamate and lactate was similarly tested, and a positive correlation was found, with a mean $r$ value of $0.274 \pm 0.044$ (SEM). The one-sample t-test on these $r$ values revealed a highly significant association $(p<0.0001)$ (Fig. 4 lower).

\section{Potassium and its Relationship With rCBF}

In 59 patients rCBF was compared with the mean potassium value. The Spearman rank correlation test demonstrated an inverse relationship between potassium and CBF $(\mathrm{r}=-0.426)$, which was significant $(\mathrm{p}=0.019)($ Fig. 5).

\section{Potassium and its Relationship With ICP}

When the mean ICP was shown to be less than $30 \mathrm{~mm}$ $\mathrm{Hg}$, the mean $\mathrm{K}^{+}$was $1.3 \pm 0.01 \mathrm{mM}(\mathrm{SEM})$, and when ICP was greater than $30 \mathrm{~mm} \mathrm{Hg}$, the mean $\mathrm{K}^{+}$was $2.3 \pm$ $0.2 \mathrm{mM}$ (SEM). An unpaired t-test revealed a highly significant relationship ( $\mathrm{p}<0.0001)$ (Fig. 6).

\section{Potassium and its Relationship With Outcome}

Patients in whom outcome was determined to be good (GOS scores of 1 and 2), poor (GOS scores of 2 and 3), or patients who were dead (GOS score of 4) had mean dialysate potassium levels of $1.71 \pm 0.01 \mathrm{mM}, 2.04 \pm 0.03$ $\mathrm{mM}, 2.21 \pm 0.06 \mathrm{mM}(\mathrm{SEM})$, respectively. In patients with good outcomes significantly lower potassium values were demonstrated than in those in the two other groups $(\mathrm{p}<0.0001)$ (Fig. 7).

\section{DISCUSSION}

Examination of the results of this study shows that dialysate potassium was increased in $20 \%$ of our patients with severe TBI (Figs. 1 and 3). This pathological, prolonged persistence of high ECF potassium, in the most severly affected patients after TBI-in contrast to animal model studies - suggests failure to restore ionic homeostasis. This implies that the normal buffering mechanisms that maintain the ionic homeostasis needed for establishment of the resting membrane potential have been overcome. This, in turn, may be a consequence of: 1) prolonged ionic leakage across agonist-operated ion channels (for example, by stretch-induced delayed depolarization): 2 ) rupture of cellular membranes associated with cell death: 3 ) failure of the sodium potassium pump (for example, due to ATP depletion: or 4) inability of astrocytes to take up more potassium.
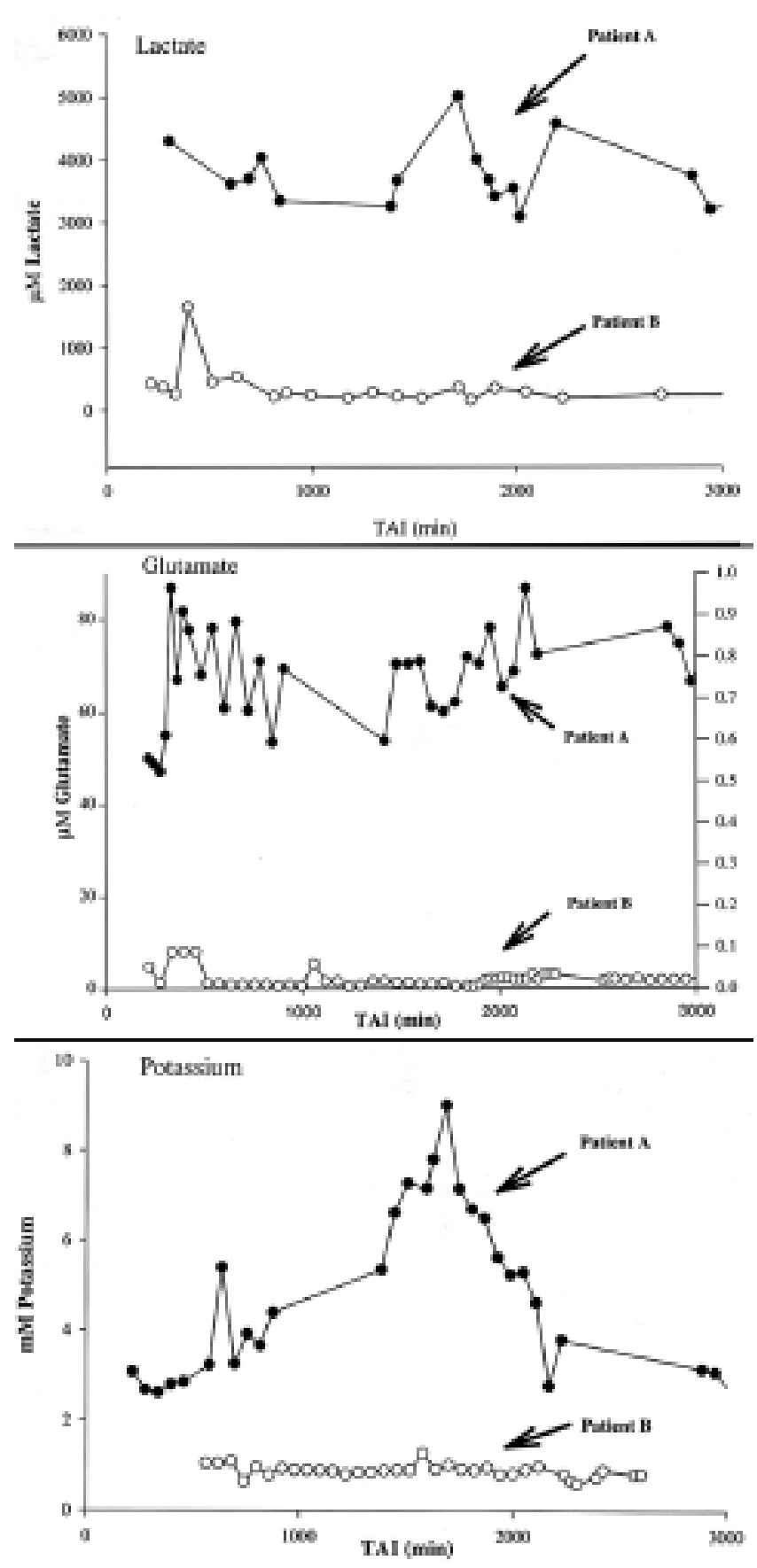

Fig. 2. Graphs depicting examples of raw dialysate data. Results obtained in patient A show high dialysate glutamate, lactate, and potassium; the mean ICP was high over $30 \mathrm{~mm} \mathrm{Hg}$, and the patient died. Results obtained in patient B show low dialysate glutamate, lactate, and potassium; the mean ICP was less than 20 $\mathrm{mm} \mathrm{Hg}$ and the patient's recovery was good. TAI = time after injury.

We have shown a close correlation $(\mathrm{p}<0.0001)$ between high glutamate and high potassium in this study (Fig. 4 left), which suggests that prolonged agonist-operated ion channel opening is likely to be an important mechanism. A similar positive correlation between $\mathrm{K}^{+}$ and glutamate has already been shown in different animal 


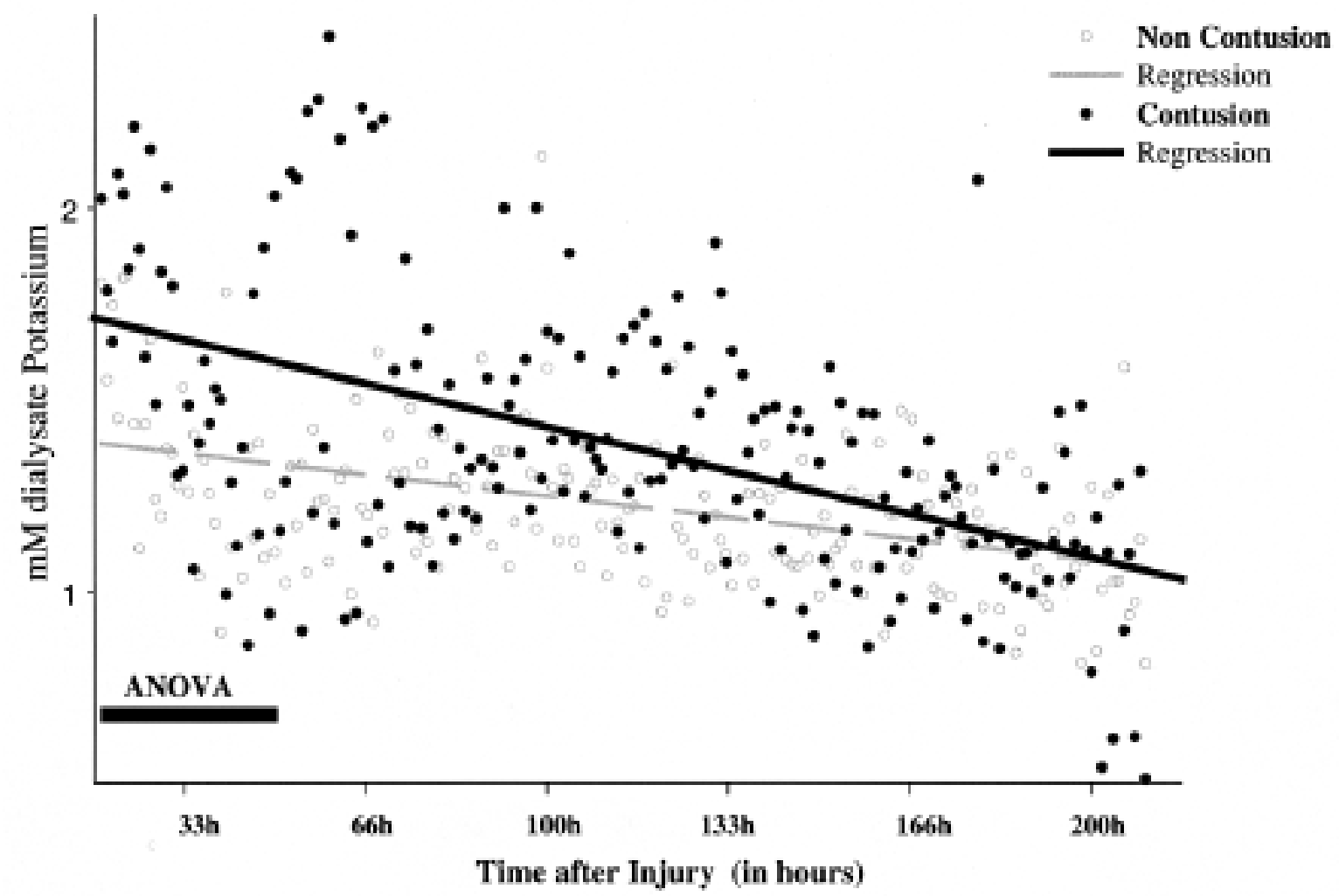

Fig. 3. Scatterplot showing distribution of the potassium values when separated into patients with and without contusions located at the site of the microdialysis probe. In patients with contusions statistically increased potassium levels were demonstrated early after trauma by regression analysis $(\mathrm{p}=0.014)$. Over time this difference disappeared.

trauma models ${ }^{8,13,16,23,27,36}$ However, to our knowledge, this is the first study in which this relationship is demonstrated in humans. We have previously shown the massive release of glutamate in certain circumstances after human TBI. ${ }^{7}$ Glutamate was particularly elevated in patients who sustained contusions. The structural amino acid, threonine, was also significantly increased, in parallel with excitatory amino acids in these patients with contusions. ${ }^{7}$ This suggests that nonvesicular excitatory amino acid release (that is, prolonged membrane rupture) due to cell death may be an important factor in patients with contusions. The exact causes of potassium efflux into the extracellular space clearly cannot be determined from this study.

\section{Microdialysis as a Technique for Estimating $\left[\mathrm{K}^{+}\right]$}

Although microdialysis has been widely used to estimate $\mathrm{ECF}\left[\mathrm{K}^{+}\right]$in both traumatic and ischemic models, ${ }^{8,16,36}$ it has not been widely used in humans. ${ }^{39}$ Microdialysis, nevertheless, has significant limitations in this role, although it is currently the only method of which we are aware, for use in humans that allows repeated, relatively safe estimation of ECF $\left[\mathrm{K}^{+}\right]$, along with other values. Extracellular fluid $\left[\mathrm{K}^{+}\right]$is rapidly buffered by several mechanisms in the normal brain, such that its increase after TBI or ischemia, or physiological activation, is usually brief and transient, as has been shown by Nilsson, et al., ${ }^{27}$ in a study in which they used a $\mathrm{K}^{+}$-sensitive microelectrode, with a time resolution of seconds. Microdialysis, on the other hand, can only be used to estimate the true ECF $\left[\mathrm{K}^{+}\right]$over a much longer time period, usually around 10 to $30 \mathrm{~min}-$ utes, and the dialysate values will be influenced by perfusion rate, perfusion fluid, and probe design, as well as changes in ECF $\left[\mathrm{K}^{+}\right.$] over the collection period.[27] The human dialysate values reported here, for example, are thus lower than the true ECF $\left[\mathrm{K}^{+}\right]$, as determined by $\mathrm{K}^{+}$sensitive microelectrode. In a recent laboratory study Stiefel, et al., [W Stiefel, personal communication, 1998] have shown that measurement of dialysate $\mathrm{K}^{+}$underestimates ECF $\left[\mathrm{K}^{+}\right]$by up to $60 \%$. Taking this into account, our dialysate values should be viewed as relative trends, not absolute numbers for true ECF $\left[\mathrm{K}^{+}\right]$. Nevertheless, the large numbers of patients and the robust statistical correlations found in this study support the conclusions drawn, although further human studies with $\mathrm{K}^{+}$-sensitive microelectrodes are needed to confirm our findings.

\section{Causes for Potassium Increase After Human TBI}

The mechanisms by which the relationship of potassium to glutamate and potassium to lactate may be explained are unknown, but analysis of our data supports the following hypotheses already established by others in in vitro or in animal models. 1) Glutamate maybe responsible for the prolonged increase in extracellular potassium, as demonstrated in our study, by opening agonist-operated $\mathrm{K}^{+}$-permeable ion channels (for example, the NMDA and AMPA channels). ${ }^{17}$ Recently Goforth, et al., ${ }^{11}$ have el- 

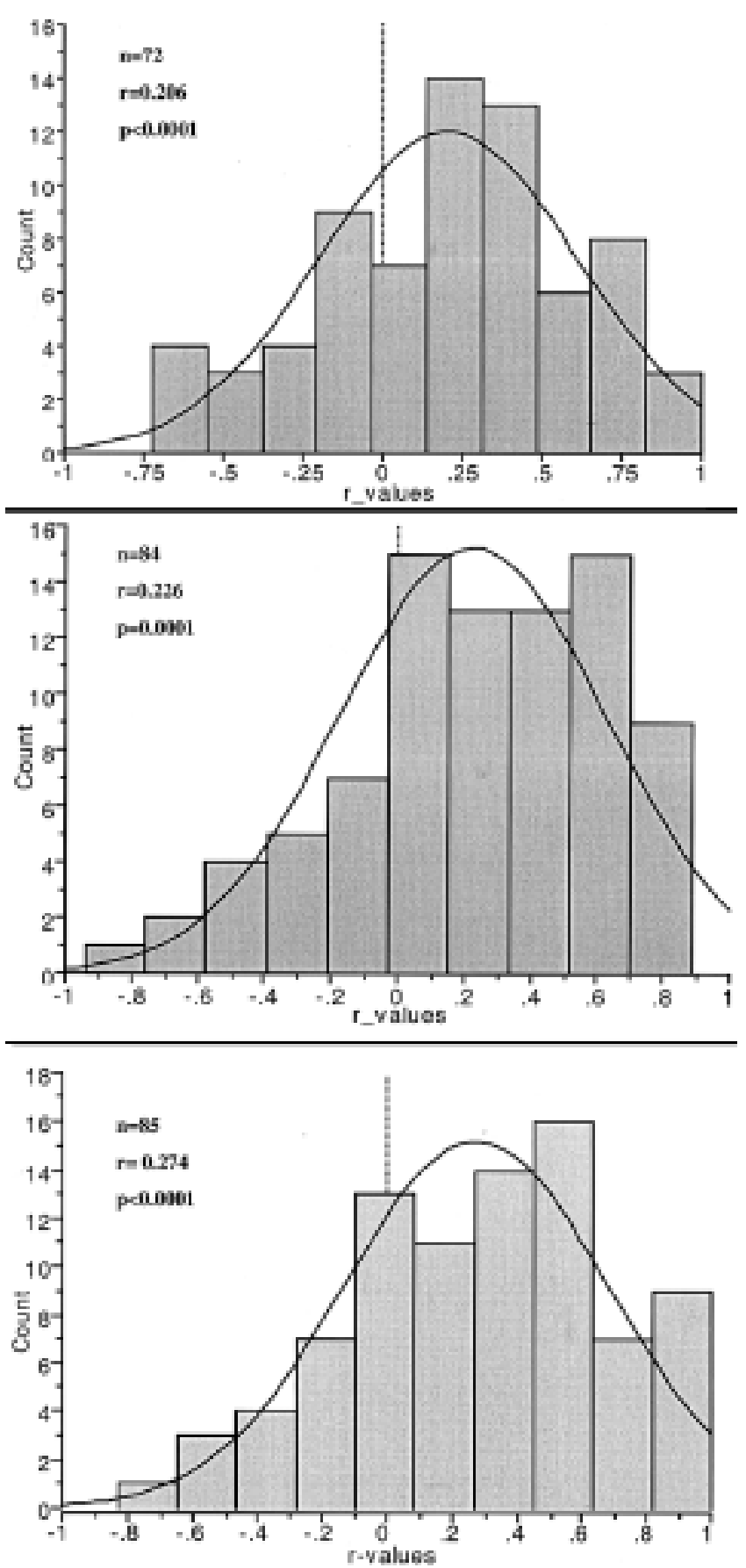

Fig. 4. Upper: Histogram showing the distribution of the $r$ values of the correlation between potassium and glutamate obtained in each patient (72 patients). Mean $r=0.206 \pm 0.04$ (SEM). A significant positive correlation between potassium and glutamate is demonstrated. Center: Histogram demonstrating the distribution of the $r$ values of the correlation between potassium and lactate obtained in each patient ( 84 patients). Mean $r=0.274 \pm 0.044$ (SEM). There was a significant positive correlation between potassium and lactate. Lower: Histogram showing the distribution of the $r$ values between glutamate and lactate obtained in each patient (85 patients). Mean $r=0.274 \pm 0.044$ (SEM). A significant positive correlation between glutamate and lactate was found.

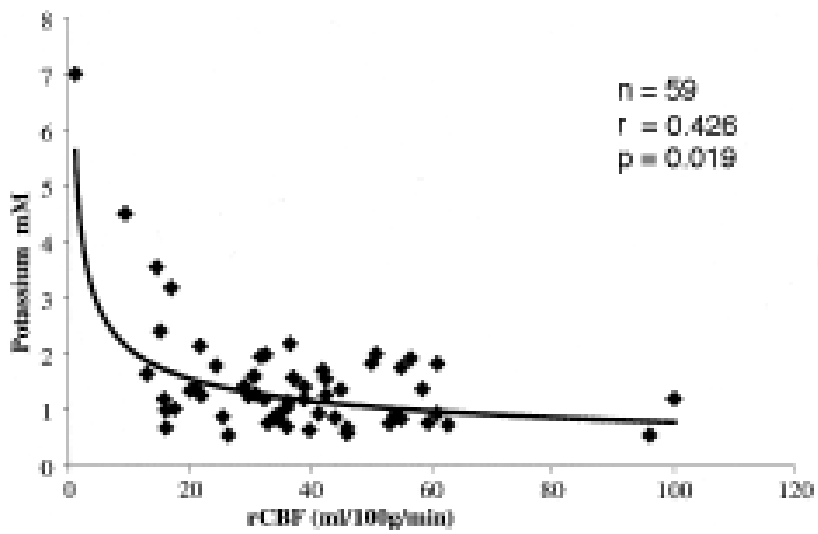

Fig. 5. Correlation between $\mathrm{rCBF}$ and dialysate potassium as seen in 59 patients. Results of the Spearman rank correlation test were significant $(\mathrm{p}=0.019)$, demonstrating an inverse relationship between potassium and CBF $(\mathrm{r}=-0.426)$.

egantly shown, by using patch-clamp techniques, that the AMPA channel becomes markedly more permeable to ions after TBI and that this is mediated by prolonged agonist (glutamate) to receptor binding. ${ }^{11}$ 2) The authors of recent patch-clamp studies, performed in mixed neuronal cultures subjected to stretch-induced shearing injury, have shown that delayed reduction of the resting membrane potential occurs, by approximately $20 \% .{ }^{37}$ This process appeared to be caused by an increase in the ionic conductance of the NMDA channel, specifically by loss of the magnesium block mechanism. ${ }^{4}$ Although this process maximized at 1 to 2 hours after injury and recovered by 24 hours, we speculate that it may contribute to the prolonged ionic disruption, which we in $20 \%$ of the patients in this study, and that its time course may be different in vivo. 3 )

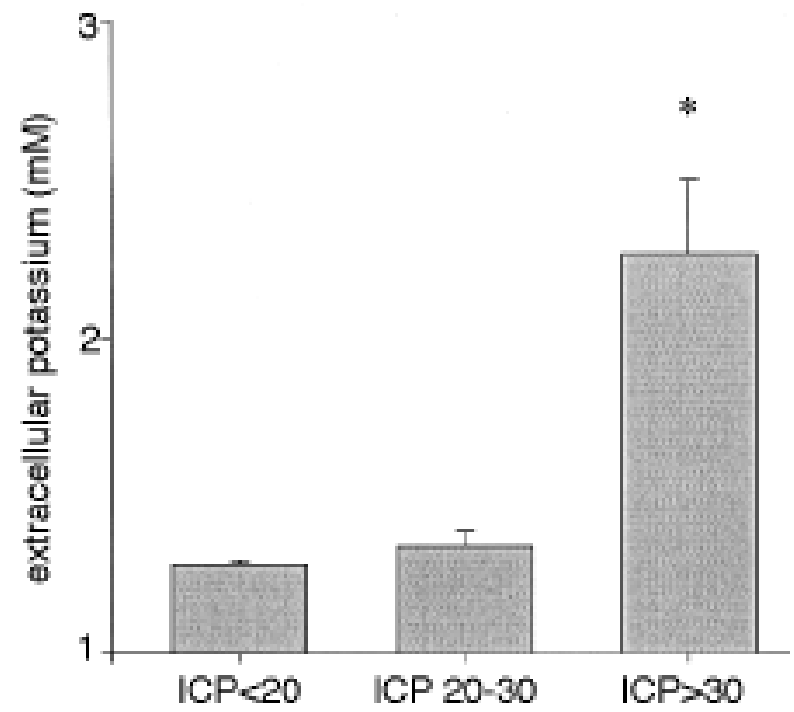

Fig. 6. Bar graph. When separated into three groups (ICP $<20$, ICP 20-30 and ICP > 30mm Hg), dialysate potassium was significantly increased in the group with ICP $>30 \mathrm{mmHg}(* \mathrm{p}<$ 0.0001) when compared with the two other groups. 


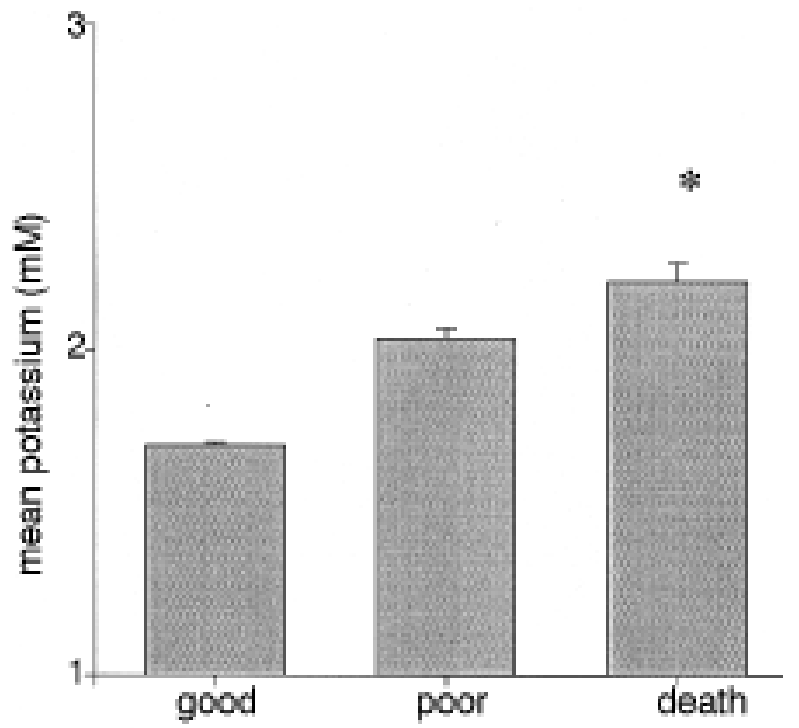

Fig. 7. Bar graph. When analyzing the outcome in three outcome groups (good, poor, and dead) an increase in dialysate potassium levels were observed in patients with worsening outcome. In patients with good outcome significantly lower potassium values were demonstrated as compared with those in the two other groups $(* \mathrm{p}<0.0001)$.

Following transient depolarization, the action of the $\mathrm{Na}^{+} / \mathrm{K}^{+}$adenosinetriphosphatase pump is an important mechanism by which neurons reestablish ionic homoestasis and repolarize. ${ }^{37}$ Persistent elevation of $\left[\mathrm{K}^{+}\right]$, as shown in this study, leads to the speculation that the $\mathrm{Na}^{+} / \mathrm{K}^{+}$ pump may be partly inactivated after TBI. The authors of several studies have recently shown that mitochondrial function is decreased after TBI. ${ }^{41,43}$ The consequent reduction in ATP generation could lead to inactivation of the $\mathrm{Na}^{+} / \mathrm{K}^{+}$adenosinetriphosphatase pump. Reduced oxidative phosphorylation, in the face of increased glycolysis (possibly glutamate induced), would also lead to increased lactate, as demonstrated in this study. Tavalin, et al., ${ }^{37}$ have shown that repletion of ATP restores the resting membrane potential after TBI in vitro, which supports this mechanism. 4) An inverse relationship was found between dialysate $\mathrm{K}^{+}$and $\mathrm{rCBF}$ in our study (Fig. 7). The highest levels of potassium were found in patients with $\mathrm{CBF}$ values below $20 \mathrm{ml} / 100 \mathrm{~g} /$ minute, which are considered ischemic. ${ }^{32}$ This suggests that ATP depletion, as described above, is an important mechanism. Paulson and Newman ${ }^{28}$ have proposed the provocative idea that the end feet of astrocytes might "feed back" on small arterioles and therefore influence rCBF by releasing potassium and, hence, altering the concentration around the arteriole, which in turn changes their state of contractility. This could explain the correlation between extracellular potassium and CBF revealed in this study, and it accords with our observation of swelling of perivascular astrocytic end feet in human TBI in ultrastructural studies. ${ }^{4,20,28}$

\section{Relationship Between Lactate, Glutamate, and Potassium}

Pellerin and Magistretti ${ }^{29}$ have shown in an in vitro study that glutamate drives glycolysis in astrocytes, resulting in increased extracellular lactate. Lactate, in turn, can then be preferentially used as a fuel for the neuron to restore ionic homeostasis. ${ }^{21,22,34,38}$ The strong correlation between glutamate and lactate observed in this study supports this hypothesis. Furthermore, Anderesen and Marmarou ${ }^{1}$ have shown that lactate generation is increased following TBI in the cat, as measured by magnetic resonance spectroscopy, even when CBF was adequate to ensure substrate delivery. This implies that factors other than ischemia can also cause lactate generation, as suggested by this and other recent studies. ${ }^{33}$ Therefore lactate may not only indicate tissue ischemia but may also reflect glutamate-driven hyperglycolysis after TBI.

\section{Consequences of Increased ECF [ $\left.\mathrm{K}^{+}\right]$}

In this study we have shown that increased dialysate $\mathrm{K}^{+}$ was strongly correlated with high ICP and with poor outcome (Figs. 6 and 7). This strongly suggests that prolonged ionic dysfunction, as demonstrated in approximately $20 \%$ of the most severely head injured patients in this study, is linked to brain swelling. We speculate that this occurs via the mechanism of $\mathrm{K}^{+}$-induced astrocyte swelling, as outlined previously. The authors of several studies have shown that increased ECF $\left[\mathrm{K}^{+}\right]$induces massive swelling of astrocytes, especially astrocytic perineuronal processes. ${ }^{4,20,29}$ This may induce a five-fold increase in astrocyte volume when ECF $\left[\mathrm{K}^{+}\right]$is high. ${ }^{5,18,19,35,41}$ Marmarou, et al., (unpublished data) have recently shown, by using magnetic resonance imaging, that the cause of brain swelling after human TBI is primarily cytotoxic edema. This finding accords with the hypothesis of $\mathrm{K}^{+}$-induced astrocytic swelling.

\section{Therapeutic Implications}

The findings of this study provide strong evidence that prolonged ionic dysfunction, leading to cytotoxic swelling, is a major cause of raised ICP and poor outcome after severe human TBI. Although the causes of this ionic dysfunction were not made clear by our study, analysis of our data implies that the best prospect for therapy, aimed at raised ICP, lies with stabilization of potassium-conducting ion channels.

\section{References}

1. Andersen BJ, Marmarou A: Functional compartmentalization of energy production in neural tissue. Brain Res 585:190-195, 1992

2. Armstead WM: ATP-dependent $\mathrm{K}^{+}$channel activation reduces loss of opiod dilation after brain injury. Am J Physiol 274: H1674-H1683, 1998

3. Armstead WM: Role of impaired cAMP and calcium-sensitive $\mathrm{K}^{+}$channel function in altered cerebral hemodynamics following brain injury. Brain Res 768:177-184, 1997

4. Ballanyi K, Grafe P, Bruggencate C: Ion activities and potassium uptake mechanisms of glial cells in guinea pig olfactory cortex sclices. J Physiol 382:159, 1987

5. Ballanyi K, Grafe P, Serve G, et al: Electrophysiological measurements of volume changes in leech neuropile glial cells. Glia 3:151-158, 1990

6. Bullock R, Zauner A, Woodward JJ, et al: Patterns of excitatory amino acid release and ionic flux after severe human head injury, in Tsubokawa T (ed): Neurochemical Monitoring in the Intensive Care Unit: Microdialysis, Jugular Venous 
Oximetry, and Near-Infrared Spectroscopy. Tokyo: Springer-Verlag, 1995

7. Bullock R, Zauner A, Woodward JJ, et al: Factors affecting excitatory amino acid release following severe human head injury. J Neurosurg 89:507-518, 1998

8. Di X, Lyeth BG, Hamm RJ, et al: Voltage-dependent $\mathrm{Na}^{+} / \mathrm{K}^{+}$ ion channel blockade fails to ameliorate behavioral deficits after traumatic brain injury in the rat. J Neurotrauma 13: 497-504, 1996

9. Forsyth R, Fray A, Boutelle M, et al: A role for astrocytes in glucose delivery to neurons? Dev Neurosci 18:360-370, 1996

10. Gill R, Andine P, Hillered L, et al: The effect of MK-801 on cortical spreading depression in the penumbral zone following focal ischaemia in the rat. J Cereb Blood Flow Metab 12: 371-379, 1992

11. Goforth PB, Ellis EF, Satin LS: Enhancement of AMPA-mediated current after traumatic injury in cortical neurons. J Neurosci 19:7367-7374, 1999

12. Hansen AJ: Effect of anoxia on ion distribution in the brain. Physiol Rev 65:101-148, 1985

13. Hirota H, Katayama Y, Kawamata $T$, et al: Inhibition of the high affinity glutamate uptake system facilitates the massive potassium flux during cerebral ischaemia in vivo. Neurol Res 17:94-96, 1995

14. Hossman K, Sakaki S, Zimmermann V: Cation activities in reversible ischemia in the rat brain cortex. Acta Physiol Scand 113:437-445, 1977

15. Kasemsri T, Armstead WM: Endothelin impairs ATP-sensitive $\mathrm{K}^{+}$channel function after brain injury. Am J Physiol 273: H2639-H2647, 1997

16. Katayama Y, Becker DP, Tamura T, et al: Massive increases in extracellular potassium and the indiscriminate release of glutamate following concussive brain injury. J Neurosurg 73: 889-900, 1990

17. Katayama Y, Maeda T, Koshinaga M, et al: Role of excitatory amino acid-mediated ionic fluxes in traumatic brain injury. Brain Pathol 5:427-435, 1995

18. Kempski OS, Volk C: Neuron-glial interaction during injury and edema of the CNS. Acta Neurochir Suppl 60:7-11, 1994

19. Kempski OS, von Rosen S, Weigt H, et al: Glial ion transport and volume control. Ann NY Acad Sci 633:306-317, 1991

20. Kuffler S: Neuroglial cells: physiological properties and a potassium mediated effect of neuronal activity on the glial membrane potential. Proc R Soc Lond (B) 168:1-21, 1967

21. Larrabee MG: Lactate metabolism and its effect on glucose metabolism in an excised neural tissue. J Neurochem 64: 1734-1741, 1995

22. Larrabee MG: Partitioning of $\mathrm{CO}_{2}$ production between glucose and lactate in excised sympathetic ganglia, with implications for brain. J Neurochem 67:1726-1734, 1996

23. Lyeth BG, Hayes RL: Cholinergic and opioid mediation of traumatic brain injury. J Neurotrauma 9 (Suppl 2):S463-S473, 1992

24. Magistretti PJ, Sorg O, Yu N, et al: Neurotransmitters regulate energy metabolism in astrocytes: implications for the metabolic trafficking between neural cells. Dev Neurosci 15:306-312, 1993

25. Mayevsky A, Doron A, Manor T, et al: Cortical spreading depression recorded from human brain using a multiparametric monitioring system. Brain Res 740:268-274, 1996

26. Nicholls JG, Martin AR, Wallace BG, et al: From Neuron to Brain: A Cellular and Molecular Approach to the Function of the Nervous System, ed 3. Sunderland, MA: Sinauer Associates, 1992

27. Nilsson P, Hillered L, Olsson Y, et al: Regional changes in interstitial $\mathrm{K}^{+}$and $\mathrm{Ca}^{2+}$ levels following cortical compression contusion trauma in rats. J Cereb Blood Flow Metab 13: 183-192, 1993

28. Paulson OB, Newman EA: Does the release pf potassium from astrocytes endfeet regulate cerebral blood flow. Science 237: 896-898, 1987

29. Pellerin L, Magistretti PJ: Glutamate uptake into astrocytes stimulates aerobic glycolisis: a mechanism coupling neuronal activity to glucose utilization. Proc Natl Acad Sci USA 91: 10625-10629, 1994

30. Pellerin L, Pellegri G, Bittar P, et al: Evidence supporting the existence of an activity-dependent astrocyte-neuron lactate shuttle. Dev Neurosci 20:291-299, 1998

31. Schousboe A, Westergaard N, Waagepetersen HS, et al: Trafficking between glia and neurons of TCA cycle intermediates and related metabolites. Glia 21:99-105, 1997

32. Schroder M, Muizelaar JP, Fatouros PP, et al: Regional cerebral blood volume after severe head injury patients with regional cerebral ischemia. Neurosurgery 42:1276-1281, 1998

33. Schurr A, Miller JJ, Payne RS, et al: An increase in lactate output by brain tissue serves to meet the energy needs of glutamate-activated neurons. J Neurosci 19:34-39, 1999

34. Schurr A, West CA, Rigor BM: Lactate-supported synaptic function in the rat hippocampal slice preparation. Science 240: 1326-1328, 1988

35 Sykova E, Vargova S, Prokopova S, et al: Glial swelling and astrogliosis produce diffusion barriers in the rat spinal cord. Glia 25:56-70, 1999

36. Takahashi HS, Manaka S, Sano K: Changes in extracellular potassium concentration in cortex and brain stem during the acute phase in experimental closed head injury. J Neurosurg 55:708-711, 1981

37. Tavalin SJ, Ellis EF, Satin LS: Inhibition of the electrogenic Na pump underlies delayed depolarization of cortical neurons after mechanical injury or glutamate. Am J Neurophysiol 77: 632-638, 1997

38. Tsacopoulos M, Magistretti PJ: Metabolic coupling between glia and neurons. J Neurosci 16:877-885, 1996

39. Valadka AB, Goodman JC, Gopinath SP, et al: Comparison of brain tissue oxygen tension to microdialysis-based measures of cerebral ischemia in fatally head injured patients. J Neurotrauma 15:509-519, 1998

40. Verweij BH, Muizelaar JP, Vinas FC, et al: Mitochondrial dysfunction after experimental and human brain injury and its possible reversal with a selective N-type calcium channel antagonist (SNX-111). Neurol Res19:334-339, 1997

41. Wuttke WA: Mechanism of potassium uptake in neuropile glial cells in the central nervous system of the leech. J Neurophysiol 63:1089-1097, 1990

42. Xiong Y, Gu Q, Peterson PL, et al: Mitochondrial dysfunction and calcium perturbation induced by traumatic brain injury. J Neurotrauma 14:23-34, 1997

43. Zhang L, Rzigalinski BA, Ellis EF, et al: Reduction of voltagedependent $\mathrm{Mg}^{2+}$ blockade of NMDA current in mechanically injured neurons. Science 274:1921-1923, 1996

Manuscript received November 15, 1999.

Accepted in final form December 22, 1999.

Support for this study was provided by the National Institutes of Health Grant No. 12587, National Institutes of Health Grant No. 12587, the Novartis Foundation the Swiss National Foundation (to M.R.), and the Reynolds Foundation (R.B.).

Address reprint requests to: Ross Bullock, M.D., Ph.D., Medical College of Virginia, Virginia Commonwealth University, P.O. Box 980631, Richmond, Virginia 23298-0631. email: mreinert@insel.ch. 